\title{
El Nobel de física i el teu portàtil
}

\author{
Josep Fontcuberta
}

Institut de Ciència de Materials - CSIC

El darrer premi Nobel de física s'ha concedit per treballs que han posat les bases per a la fabricació de discs durs cada vegada més petits. Quins són els avenços que ho han fet possible?

Paraules clau: magnetoresistència gegant, spin electrònic, ferromagnetisme, enregistrament magnètic, disc dur, premi Nobel de Física.

En pocs anys la mida dels discs durs, i la dels aparells que els contenen (portàtils, iPods, alguns mòbils...) ha anat minvant contínuament. Vegem el que ha calgut per fer-ho possible.

\section{Enregistrament magnètic de dades}

L'enregistrament magnètic de dades digitals consisteix en la imantació d'un domini magnètic en un sentit per representar un 1 o en sentit contrari per al 0 (fig. 1).

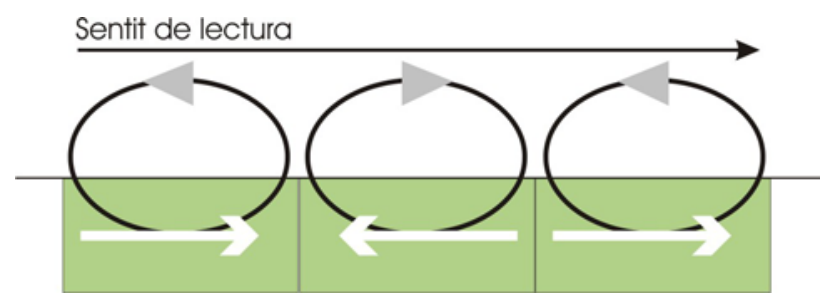

Figura 1. El sentit de la imantació de cada domini magnètic representa els valors 1 o 0 de cada bit d'informació. Noteu que entre dos dominis, el camp magnètic resultant és vertical: cap a munt o cap avall, segons si la imantació dels dominis està dirigida a la dreta o a l'esquerra.

Per llegir aquesta informació cal apropar-hi un sensor que detecti el sentit del camp i traduir-lo en senyals elèctrics d'un i zeros.
Ara bé, la miniaturització comporta disminuir la mida dels dominis, fent el seu camp més dèbil i necessitant, per tant, lectors cada vegada més sensibles i petits. Com aconseguir-ho?

\section{La magnetoresistència gegant}

La resposta tindria relació amb un efecte relacionat amb el spin de l'electró, el seu moment magnètic intrínsec. Tradicionalment l'electrònica no havia tret cap profit d'aquesta propietat (fig. 2).

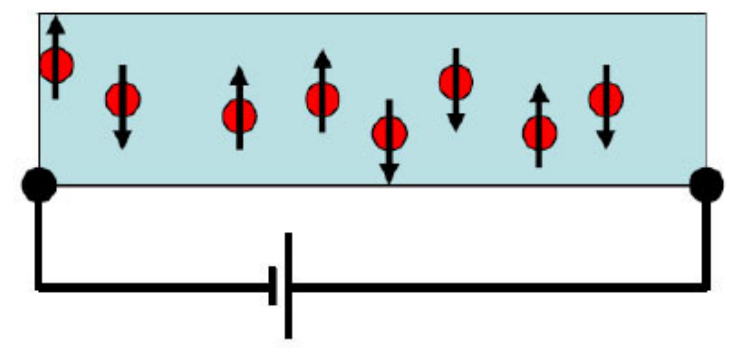

Figura 2. En un conductor els electrons tenen diferent valor de spin (positiu o negatiu), una propietat que normalment no s'aprofita en els circuits.

En canvi, la progressiva utilització pràctica de les propietats del spin constitueix una nova branca de l'electrònica que ja s'anomena spintrònica, que pot oferir resultats sorprenents.

Lord Kelvin ja havia descobert que si un conductor elèctric com el ferro estava sotmès a un camp magnètic, la seva resistència variava segons 
la direcció del camp magnètic. El canvi de resistència és petit, entorn de l'u per cent, però ha estat suficient per generar tota una generació de sensors magnètics d'importància tecnològica i industrial (sensors AMR).

El 1988 els físics Albert Fert i Peter Grünberg (fig. 3), de forma independent, van descobrir que en determinades condicions un canvi de sentit del camp magnètic pot produir grans variacions (de fins a un $50 \%$ ) en el valor de la resistència elèctrica de determinats conductors. És el que es coneix com a magnetoresistència gegant (GMR, sigles en anglès) i que els ha valgut el premi Nobel.
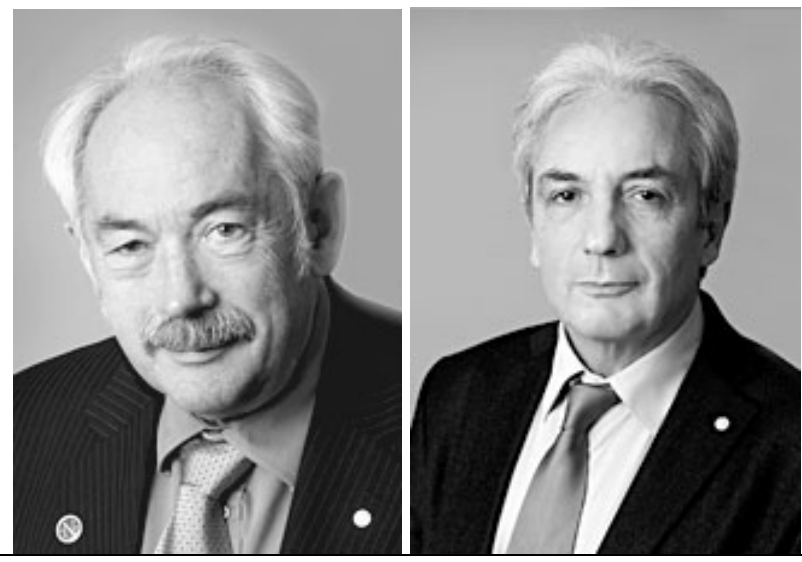

Figura 3. El francès Albert Fert (esquerra) i l'alemany Peter Grünberg, guardonats amb el premi Nobel de física el 2007. (Font: nobelprize.org)

La base del treball de Fert va consistir en elaborar i estudiar el comportament de capes superposades, molt primes, de diversos materials: dues de ferromagnètiques $(F)$ i una d'intermèdia no magnètica (NM) (fig. 4).

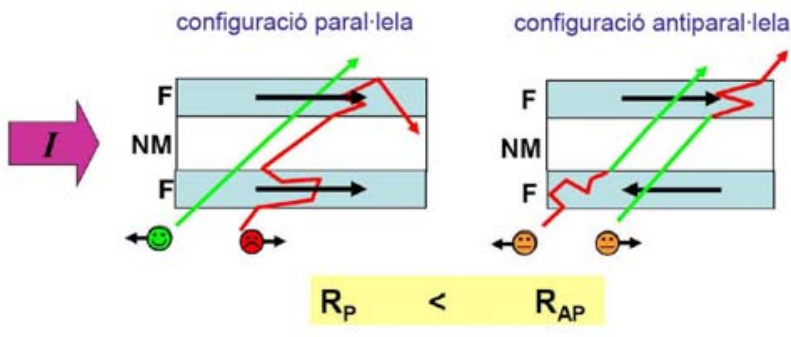

Figura 4. Els electrons de spin paral-lel al camp magnètic sofreixen més xocs (trajectòries vermelles) i mostren, doncs, més resistència que no els que el tenen en sentit contrari al camp (trajectòries verdes).

A la fig. 4 els electrons són empesos pel camp elèctric a viatjar cap a la dreta. Viatgen a través de la capa no magnètica, però també de les ferromagnètiques que, en general, tenen resistivitat, més gran. Un cop allà, els electrons de spin antiparal-lel al camp magnètic de la capa hi troben menys resistència que els que el tenen en sentit paral-lel.

Si les dues capes ferromagnètiques estan magnetitzades en el mateix sentit, això facilita el pas a la meitat d'electrons amb el spin adequat, antiparal.lel (verd a la fig. 4), mentre que el dificulta als que el tenen paral.lel (en vermell).

Tot plegat fa que quan les capes ferromagnètiques estan magnetitzades en el mateix sentit bona part dels electrons hi tenen circulació fàcil, disminuint la resistència del muntatge (fig. 5); en canvi, si estan magnetitzades en sentits contraris, la dificultat per circular afecta a tots els electrons, fent que la resistència sigui més gran.

configuració paral·lela

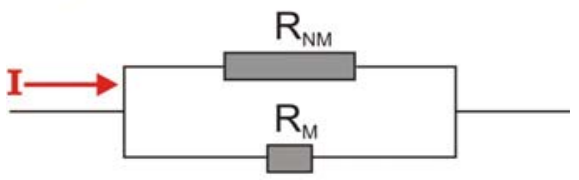

configuració antiparal·lela

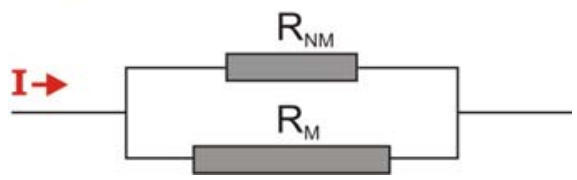

Figura 5. En la configuració antiparal-lela la resistència elèctrica de les capes magnètiques $\left(R_{M}\right)$ és superior, disminuint la intensitat (I) del corrent. La resistència de la capa no magnètica $\left(R_{N M}\right)$ no canvia però sí la total.

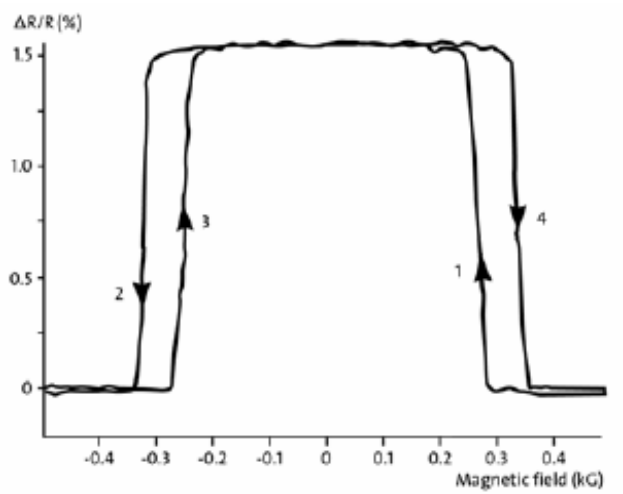

Figura 6. La variació de la resistència d'un "sandvitx" Fe-Cr-Fe a temperatura ambient és només de l'1,5\%, segons dades de Grünberg. (Font: nobelprize.org) 
Després de moltes provatures amb centenars de materials, Fert va trobar que una de les combinacions que donava bons resultats era una capa de crom (no magnètic) entre dues de ferro (ferromagnètic). També s'ha fet servir coure com a material no magnètic.

Per potenciar aquest efecte s'han utilitzat dispositius formats per moltes més capes, repetint la disposició Fe-Cr-Fe (fig. 7).

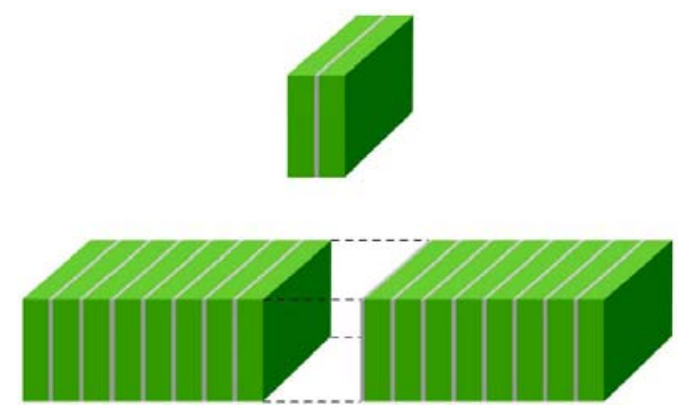

Figura 7. A dalt, representació d'una tricapa $\mathrm{Fe}-\mathrm{Cr}$ Fe, com les utilitzades pel grup de Grünberg. A sota, multicapa $(\mathrm{Fe}-\mathrm{Cr})_{\mathrm{n}}$, com les utilitzades pel grup de Fert, amb valors de $n$ que arriben a 60. Totes les capes tenen un gruix de l'ordre dels nanòmetres. (Font: nobelprize.org)

Utilitzant el sistema multicapes, efectivament, el canvi de resistència queda molt accentuat (fig. 8).

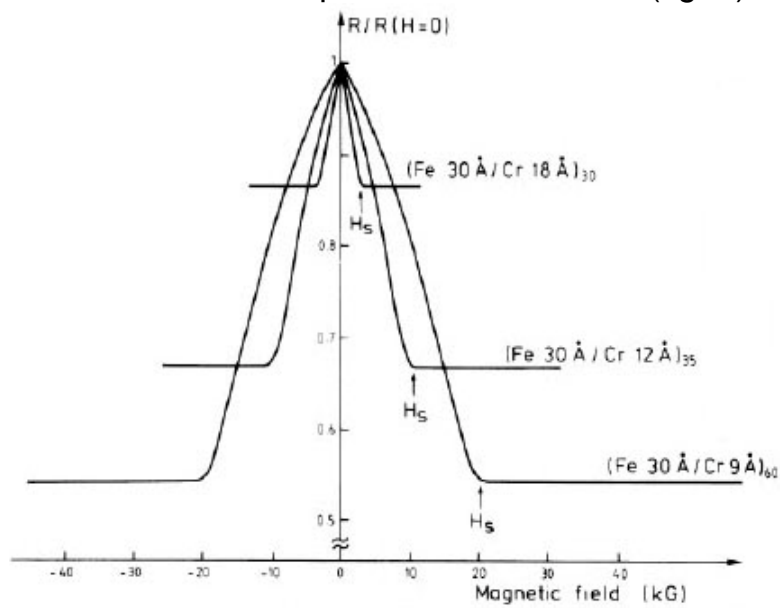

Figura 8. Variació de la resistència per a multicapes Fe-Cr a 4,2 K, segons Fert. Com s'hi pot veure, com més prima és la capa de $\mathrm{Cr}$, més intens és l'efecte. La disminució de la resistència s'apropa al $50 \%$. (Font: nobelprize.org)

Aquestes capes són extraordinàriament primes: en la fig. 8 una de les capes de crom fa 9 àngstroms, mentre que les de ferro es mantenen en 30
( 0,9 i $3 \mathrm{~nm}$ respectivament). Tenint en compte que el diàmetre dels àtoms és de l'ordre d'un àngstrom, vol dir que estem parlant de gruixos de molt pocs àtoms.
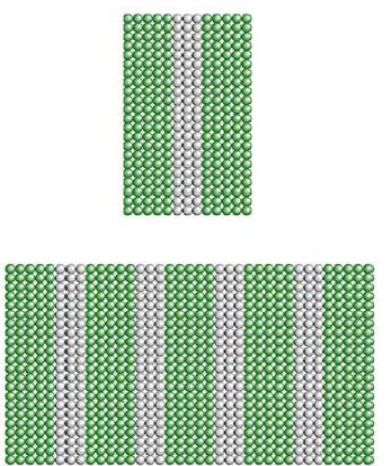

Figura 9. Visualització dels àtoms en una tricapa (dalt) i en una multicapa (a sota). (Font: nobelprize.org)

\section{Aplicacions pràctiques}

Si les bases científiques de la magnetoresistència gegant les posaren Fert i Grünberg el 1988, el 1997 ja es comercialitzava el primer dispositiu que la utilitzava per llegir informació en discs magnètics (fig. 10).

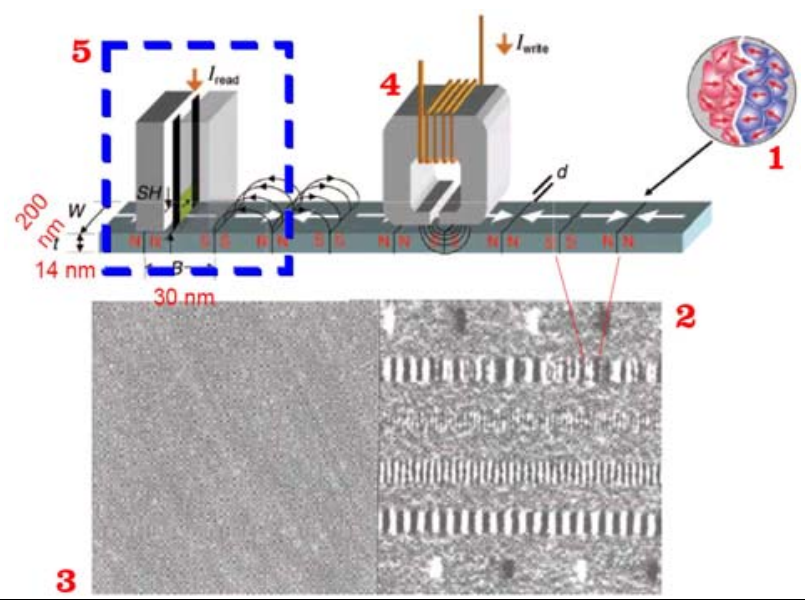

Figura 10. (1) Visualització de la frontera entre dominis magnètics. (2) Visualització dels dominis sobre la superfície del disc, indicats en tons clars i foscos. (3) La superfície del disc es pot considerar atòmicament plana. (4) Capçal de gravació. (5) Capçal de lectura que incorpora l'efecte de GMR. Noteu que els dominis magnètics fan només $30 \mathrm{~nm}$ de llargada.

Quan el sensor arriba a una "paret de domini", on les línies de camp magnètic són verticals, el 
camp magnètic de cada capa (en direcció horitzontal) es suma (vectorialment) a la imantació del sensor de manera que aquesta s'inclina amunt o avall segons el sentit de la imantació de la paret de domini (fig. 11).

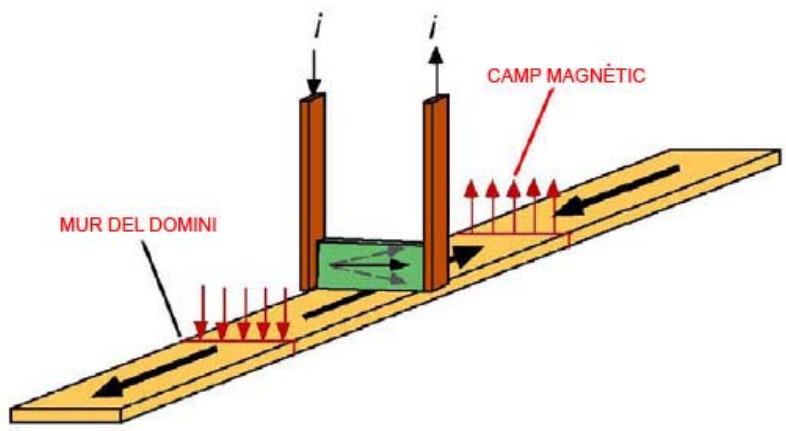

Figura 11. Per la multicapa passa un corrent que depèn de la seva resistència. Aquesta varia quan el lector travessa una paret de domini, és a dir, aquella zona on les línies del camp magnètic entren o surten del disc perquè estan en contacte dos dominis de polaritat diferent.

Aquesta variació del camp magnètic fa variar la resistència de la multicapa. Com que està sotmesa a un voltatge constant, cada canvi de domini produeix una variació de la intensitat del corrent que hi circula.

Finalment, aquesta variació de la intensitat es tradueix en impulsos binaris que reprodueixen la informació llegida en el disc.

\section{Perspectives de futur}

La miniaturització que permet la GMR es pot evidenciar en la imatge següent (fig. 13).

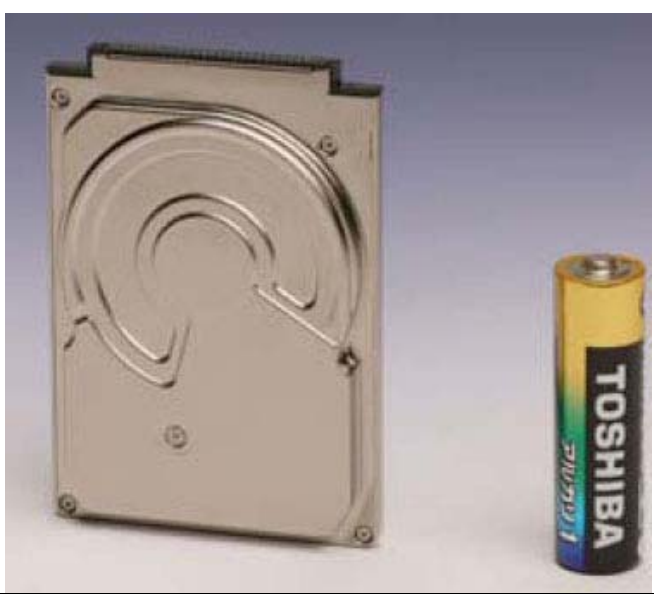

Figura 13. Un disc dur ja pot tenir una mida de pocs centímetres, com és aquest d'un iPod.
Actualment també s'estan investigant altres tècniques de lectura de dades, encara més sensibles, que podrien permetre reduir més la mida dels dominis magnètics $i$, per tant, augmentar la densitat d'informació guardada. Una línia prometedora d'investigació consisteix en utilitzar "sandvitxos" amb dues capes ferromagnètiques però amb una capa aïllant entremig (fig. 14).

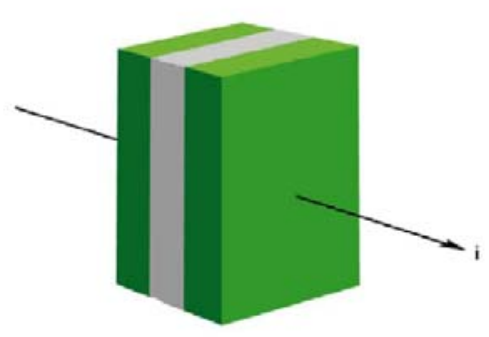

Figura 14. Sandvitx de dues capes ferromagnètiques (en verd) separades per una capa aïllant (per exemple, de $\mathrm{Al}_{2} \mathrm{O}_{3}$ que fa de barrera d'efecte túnel). El gruix de cada capa és de l'ordre dels nanòmetres. (Font: nobelprize.org)

Tot i la capa aïllant, l'efecte túnel permet el pas de corrent entre les dues capes metàl-liques. Quan les dues capes ferromagnètiques estan magnetitzades en paral-lel, la resistència és petita, mentre que en configuració antiparal-lela esdevé molt més alta. S'arriben a produir diferències de resistència de l'ordre del 500\%. S'anomena magnetoresistència d'efecte túnel (TMR, sigles en anglès).

Una altra tècnica que ajudarà a augmentar la densitat d'informació són els mitjans d'enregistrament perpendicular, on els dominis són perpendiculars a la superfície del disc (fig. 15).

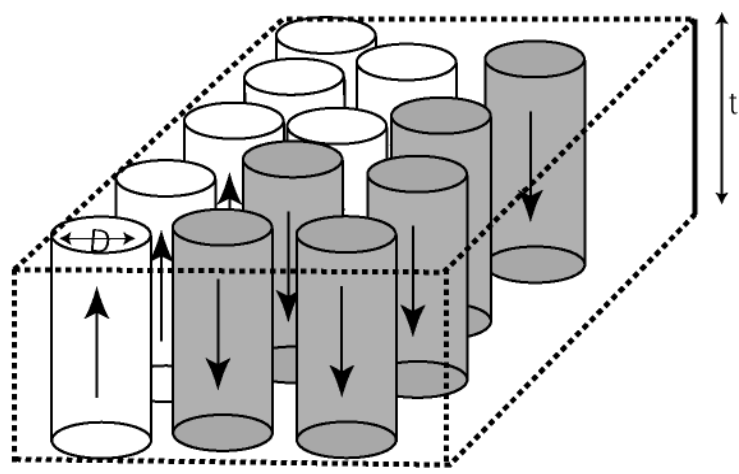

Figura 15. Dominis magnètics perpendiculars a la superfície del disc. El seu diàmetre (D) és unes 5 vegades menor que el gruix $(\mathrm{t})$ de la capa. (Font: http://www.guzik.com/solutions_chapter7.shtml) 


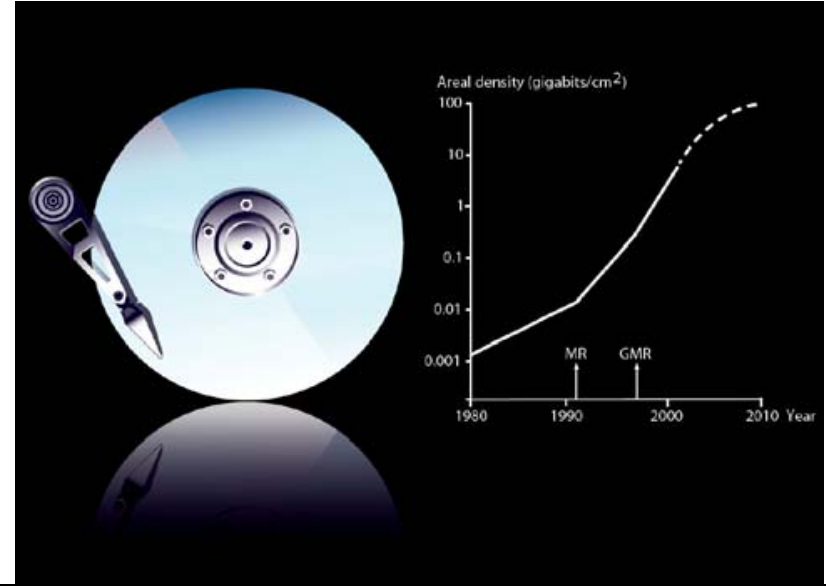

Figura 16. Gràcies a la continuada miniaturització dels lectors de discs durs, la seva densitat d'informació ha anat augmentant i es preveu augmentarla encara més.

Com a conseqüència d'aquestes i altres noves tècniques s'espera que la densitat d'emmagatzematge de dades passi (fig. 16) dels 0,001 $\mathrm{Gbit} / \mathrm{cm}^{2}$ el 1980 a prop de 100 el 2010. Això suposaria multiplicar-la 100.000 vegades en només 30 anys.

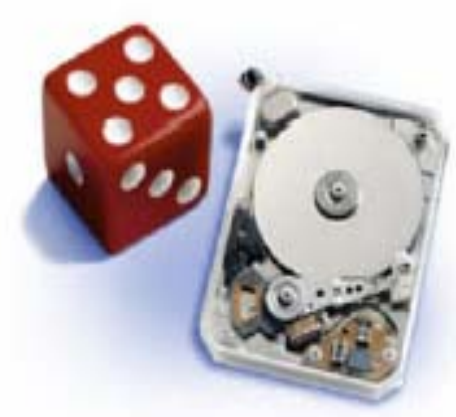

Figura 17. Disc dur de Toshiba de $2 \mathrm{~cm}$ de costat, utilitzat en càmeres fotogràfiques i mòbils.

Per altra banda, els sensibles i menuts sensors que va produint la nova ciència de la spintrònica segurament aniran trobant cada vegada més aplicacions (fig. 18).

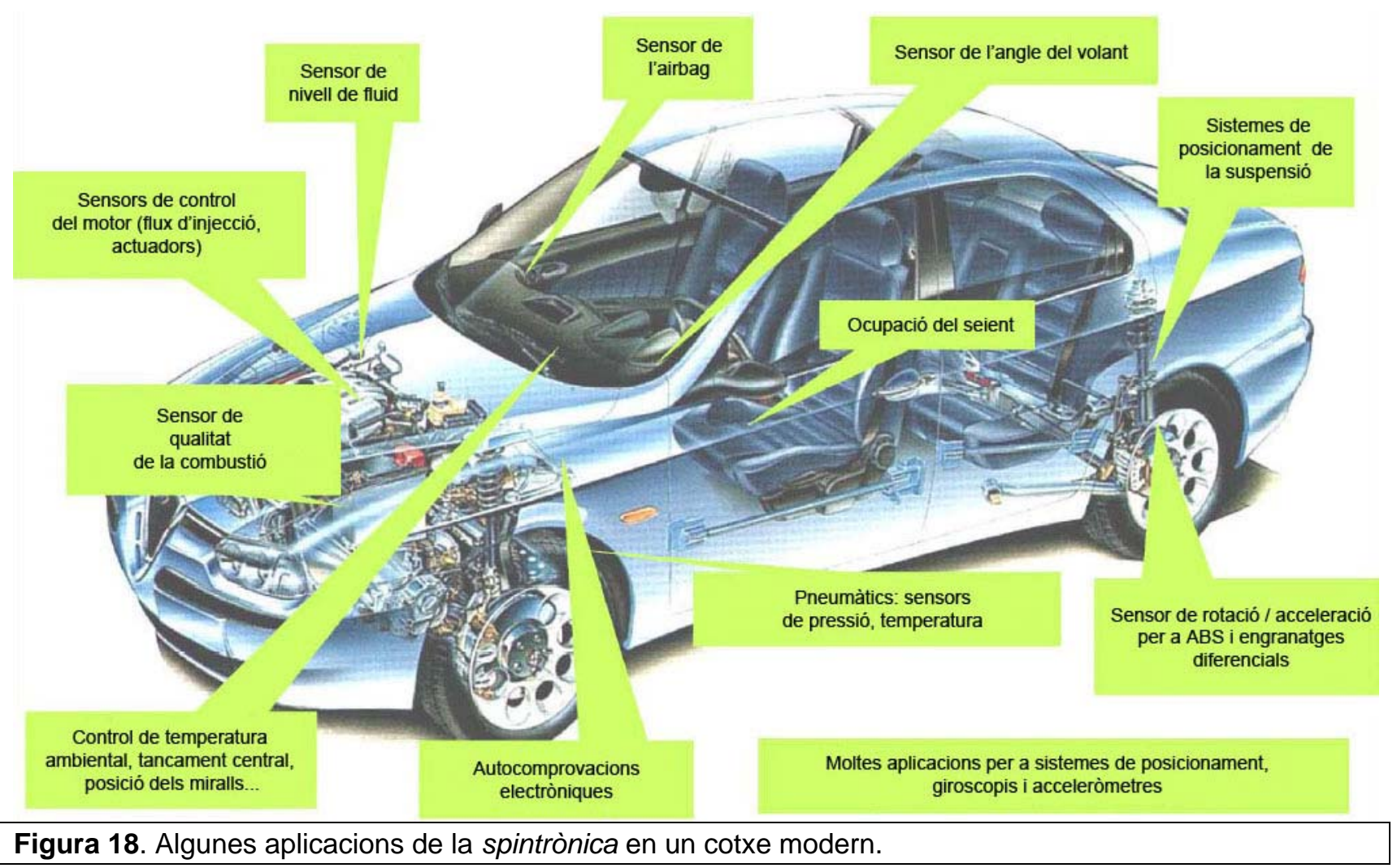

